\title{
Oportunidades de negocio y tendencias medioambientales
}

\section{Business Opportunities and Environmental Trends}

\section{Oportunidades de negócio e tendências meio ambientais}

\author{
Jessica Nájera Ochoa*
}

Fecha de recibido: 19 de mayo de 2017

Fecha de aprobado: 1 de septiembre de 2017

Doi: http://dx.doi.org/10.12804/revistas.urosario.edu.co/empresa/a.5740

Para citar: Nájera Ochoa, J. (2018). Oportunidades de negocio y tendencias medioambientales. Universidad \& Empresa, 20135), 13-50. Doi: http://dx.doi.org/10.12804/revistas.urosario.edu.co/empresa/a.5740

\section{RESUMEN}

Las tendencias medioambientales presentan amenazas pero también ofrecen oportunidades de negocio sustentables para las empresas, ya que generan nuevos tipos de bienes y servicios. El objetivo de esta investigación es estudiar cómo las empresas aprovechan las oportunidades de negocio derivadas del cambio medioambiental para el desarrollo de ventaja competitiva sostenible. Se determinó, para una muestra de estudio de empresas mexicanas, si identifican las oportunidades de negocio derivadas de las tendencias medioambientales, si reconocen cómo aprovecharlas y si les es posible acceder a dichas oportunidades para su beneficio. El tipo de investigación es aplicada y tecnológica, de corte transversal y alcance correlacional; el enfoque es mixto, cualitativo y cuantitativo. Para el procesamiento y análisis de los datos se aplicaron pruebas de normalidad de la muestra y de confiabilidad del instrumento de investigación, así como pruebas estadísticas paramétricas, y se obtuvieron los coeficientes de correlación y de determinación de las variables de investigación. Los resultados de esta investigación muestran una relación lineal positiva y alta entre las variables, lo que indica que el conocimiento de las tendencias medioambientales, la disponibilidad de recursos y

* Doctora en Ciencias Administrativas, maestra en Administración de Negocios y licenciada en Ciencias de la Informática por el Instituto Politécnico Nacional, Ciudad de México, México. Docente-Investigador del Centro de Investigación e Innovación en Tecnologías de la Información y Comunicación, Ciudad de México, México. Correo electrónico: jnajerao@yahoo.com.mx 
la actitud innovadora permiten aprovechar las oportunidades de negocio derivadas del cambio medioambiental, independientemente del tamaño de la empresa.

Palabras clave: Competitividad, ventaja competitiva, sustentabilidad, economía verde, tendencias medioambientales, oportunidades de negocio.

\section{ABSTRACT}

Environmental trends represent threats but also opportunities for business in respect to new kinds of goods and services. This research aims to study how companies take advantage of business opportunities from environmental change for the development of a sustainable competitive advantage. It was determined for a study sample of Mexican companies: if they are able to identify the business opportunities arising from environmental trends; if they recognize how to take advantage of them and if it is possible for them to reach these opportunities for their benefit. The applied research type is technological, cross-sectional and correlational. The approach is mixed, quantitative and qualitative. For data processing and analysis sample normality test, research instrument reliability, parametric statistical test, and the correlation and determination coefficients were used. The results of this study show a high and positive linear relationship between variables, which implies that the knowledge about environmental trends, the availability of resources and the innovative attitude enable and facilitate companies to take advantage of business opportunities from environmental change, regardless of the company's size.

Keywords: Competitiveness, competitive advantage, sustainability, green economy, environmental trends, business opportunities.

\section{RESUMO}

As tendências meio ambientais apresentam ameaças, mas também oferecem oportunidades de negócio sustentáveis para as empresas pela geração de novos tipos de bens e serviços. $\mathrm{O}$ objetivo desta pesquisa és estudar como as empresas aproveitam as oportunidades de negócio derivadas da mudança ambiental para o desenvolvimento de vantagem competitiva sustentável. Determinou-se para uma amostra de estudo de empresas mexicanas: se identificam as oportunidades de negócio derivadas das tendências meio ambientais; se reconhecem como aproveitá-las e se lhes é possível aceder a ditas oportunidades para o seu benefício. O tipo de pesquisa é aplicado e tecnológico, de corte transversal e alcance de correlação. O enfoque é misto, qualitativo e quantitativo. Para o processamento e análise de dados se aplicaram provas de normalidade da amostra e de confiabilidade do instrumento de pesquisa, assim como provas estatísticas paramétricas e se obtiveram os coeficientes de correlação e de determinação das variáveis de pesquisa. Os resultados desta pesquisa mostram uma relação lineal positiva e alta entre as variáveis, o que indica que: o conhecimento das tendências meio ambientais, a disponibilidade de recursos e a atitude inovadora, permitem aproveitar as oportunidades de negócio derivadas da mudança ambiental, independentemente do tamanho da empresa.

Palavras-chave: Competitividade, vantagem competitiva, sustentabilidade, economia verde, tendências meio ambientais, oportunidades de negócio. 


\section{INTRODUCCIÓN}

El cambio medioambiental, en gran parte impulsado por la demanda humana de recursos, el aumento del nivel de vida y el crecimiento de la población mundial, está acelerando y generando nuevos desafíos. Las tendencias medioambientales presentan amenazas y vulnerabilidades, pero también ofrecen nuevas oportunidades de negocio sustentables en el ámbito de la economía verde. Sin duda, las empresas que enfrenten y asimilen más pronto esta realidad serán las que prosperen y se mantengan competitivas en un mundo que cambia rápidamente, en donde factores como el cambio climático y la disminución de la disponibilidad de los recursos naturales, tales como el agua, darán forma a las futuras pérdidas y ganancias y orientarán los nuevos mercados (UNEP, 2013).

El valor de las empresas está en riesgo debido a los cambios en el estado del medioambiente mundial. Los riesgos son altos, pero al mismo tiempo se presentan nuevas e interesantes oportunidades de negocio para las empresas. Evaluar las implicaciones de las tendencias medioambientales en todo el ciclo de vida del producto, desde la extracción de materias primas, pasando por el procesamiento de los materiales, fabri- cación, distribución, uso, reparación y mantenimiento, y la eliminación o reciclaje (UNEP, 2012), e incorporar dichas tendencias en la planificación y los modelos empresariales, permitirá mejorar la competitividad de las empresas, reducir la degradación ambiental y mejorar el bienestar humano (UNEP, 2013).

Las empresas, ciudades y naciones están adquiriendo conciencia de que así como sufren penalidades económicas por no ser sustentables, también pueden obtener beneficios económicos al adoptar seriamente la sustentabilidad (Hargroves \& Smith, 2005). Existe evidencia de experiencias empresariales internacionales de éxito de la economía verde, que tienen como protagonistas empresas que integran tanto en sus prácticas administrativas, como en su misión y en sus estrategias, la preocupación por el medioambiente y el desarrollo sustentable. Son casos de compañías cuya inquietud no deriva de una actitud meramente legalista o instrumental del interés ambiental, sino de una postura estratégica o innovadora, que implica incluir el medioambiente como un componente esencial de la estrategia y desarrollar una visión, un compromiso y un liderazgo social y ambiental coherente con los propios valores corporativos (Lara, Lizarralde \& Ferro, 2010). 
Este trabajo de investigación tiene el propósito de estudiar cómo las empresas, más allá de solo apegarse al cumplimiento de la regulación gubernamental y sobrellevar las dificultades originadas por las tendencias medioambientales, pueden aprovechar las diversas oportunidades de negocio particulares para su sector e industria, en el nuevo entorno de la economía verde, determinando si conocen las tendencias medioambientales propias del territorio mexicano, si identifican las oportunidades de negocio derivadas de las mismas, si reconocen cómo aprovecharlas y si les es posible acceder a ellas para su beneficio.

El contenido de este trabajo está estructurado en cuatro capítulos. En el primero, titulado Revisión de la literatura, se señala la relevancia de la economía verde para el crecimiento económico y el desarrollo, pues mejora el bienestar humano y a su vez procura el cuidado del medioambiente; además, se presenta el cambio medioambiental y sus fuerzas motrices, población y desarrollo económico, como factores que afectan el funcionamiento del sistema Tierra provocando, entre otros, el calentamiento terrestre, el adelgazamiento de la capa de ozono, la pérdida de la biodiversidad, la erosión y desertificación, así como eventos más frecuentes y severos de clima extremo.
También se presentan las principales tendencias medioambientales y sus implicaciones más relevantes para las empresas, así como las oportunidades de negocio derivadas de ellas para sectores clave de la actividad económica; finalmente, se realiza una revisión acerca de la ventaja competitiva, las estrategias aplicables para alcanzarla, su relación con la tecnología e innovación y los beneficios y mecanismos de la transferencia tecnológica.

En el segundo capítulo se aborda el método de investigación y se plantea la situación problemática, el problema de investigación, los objetivos y la justificación de la misma, estableciendo el tipo de investigación, su finalidad, alcance, corte y enfoque, así como el tipo de diseño de la investigación; posteriormente, son definidos el universo, población y muestra de estudio, indicando el tipo de muestreo, la estratificación de la muestra y la selección del instrumento de investigación.

En el tercer capítulo, Resultados y discusión, se presentan los resultados de la investigación, obtenidos a través del análisis multivariable para la comprobación de las hipótesis planteadas en la investigación. Los resultados obtenidos muestran que existe una relación lineal estrecha y positiva entre las variables: 
conocimiento, disponibilidad de recursos y actitud innovadora para el aprovechamiento de las oportunidades de negocio de las tendencias medioambientales.

Finalmente, en el último apartado se presentan las conclusiones del trabajo de investigación, así como las limitaciones y recomendaciones para investigaciones futuras.

\section{REVISIÓN DE LITERATURA}

\subsection{Economía verde}

El desarrollo sustentable es aquel que satisface las necesidades humanas presentes sin comprometer las posibilidades de las generaciones futuras de satisfacer las propias, garantizando el equilibrio entre el crecimiento económico, el cuidado del medioambiente y el bienestar social (UNEP, 1987).

Por su parte, la economía verde mejora el bienestar del ser humano y la equidad social, a la vez que reduce significativamente los riesgos ambientales y la escasez de recursos naturales, tiene bajas emisiones de carbono, utiliza los recursos de forma eficiente y es socialmente incluyente (UNEP, 2012); además, busca aumentar los ingresos y la creación de empleos como consecuencia de inversiones públicas y privadas que estén destinadas a reducir las emisiones de carbono y la contaminación, promover la eficiencia energética así como el uso de los recursos y evitar la pérdida de diversidad biológica y de servicios de los ecosistemas (Herrán, 2012).

La economía verde ofrece una oportunidad para promover el desarrollo integral incorporando sus dimensiones económicas, sociales y ambientales, genera oportunidades y supone, según el UNEP (2012):

- La conciliación del crecimiento de la actividad económica y comercial con la gestión sostenible de los recursos y el fortalecimiento de la protección ambiental.

- La inversión en las tecnologías agrícolas que permitan una utilización más sostenible del suelo y de los recursos naturales, en general.

- La reducción de las emisiones de carbono.

- La promoción, diseminación e inversión en energías renovables.

- El manejo ambientalmente sostenible de los residuos.

- La adecuada gestión de los productos químicos.

- La promoción de patrones de consumo y producción sostenibles, con los países desarrollados tomando el liderazgo en la implementación de medidas. 
- La promoción de un hábitat social sostenible, mediante la utilización de tecnologías limpias en la construcción y la creación de oportunidades de empleo en la industria.

- La promoción de la conciencia ecológica, la educación ambiental y la responsabilidad social.

La economía verde promueve el desarrollo y la industrialización basada en la eficiencia de recursos, asegurando un acceso fiable, local y asequible a energía y tecnología, así como el mejoramiento de la eficiencia en el uso de recursos, lo que incide positivamente en el incremento de la competitividad (UNEP, 2012).

Los actuales desafíos en materia económica, ambiental y social han llevado a México a enfrentar un dilema: o seguir creciendo a tasas relativamente bajas con un alto costo para el medioambiente y para los recursos naturales, $\mathrm{y}$ un profundo rezago social, o cambiar su patrón de desarrollo por un crecimiento económico sostenido e incluyente, que asegure la provisión de los bienes y servicios ambientales de los cuales depende el desarrollo del país y el bienestar de la sociedad (SEMARNAT \& INECC, 2014).

Iniciar una transición efectiva hacia una economía verde requiere de la participación e inversión de los sectores públicos y privados en diferentes rubros, entre los que destacan la agricultura, la energía, los bosques, el turismo, el transporte, la manufactura, las ciudades, la pesca, los desperdicios y el agua. Algunas de las inversiones verdes a incentivar son las tecnologías de energía renovable, la eficiencia energética tanto en edificios de nueva construcción, como en los ya existentes, los transportes sostenibles y la agricultura sostenible (UNEP, 2009).

La implementación actual de un modelo global de economía verde exige cambios en la matriz productiva de los estados, lo cual debe estar apoyado a través de incentivos económicos instituidos de forma efectiva, así como por medidas políticas a gran escala que cuenten con un compromiso de carácter internacional (Serrano y Carrillo, 2011).

\subsection{Cambio medioambiental}

El cambio medioambiental, también denominado cambio ambiental global, es un concepto más amplio que el de cambio climático, al cual incluye. Se refiere al conjunto de cambios ambientales que se derivan de las actividades humanas sobre el planeta, específicamente aquellos que surgen en los procesos que determinan el funcionamiento del sistema Tierra, 
provocando, entre otras graves afectaciones, el calentamiento terrestre, el adelgazamiento de la capa de ozono, la modificación y pérdida de la biodiversidad, la erosión y desertificación, las precipitaciones ácidas y el desequilibrio de nutrientes en los sistemas acuáticos, así como eventos más frecuentes y severos de clima extremo, como huracanes, tornados, inundaciones, deslaves, heladas, sequías e incendios forestales (Grupo Intergubernamental de Expertos sobre el Cambio Climático, 2002).

\subsubsection{Fuerzas motrices}

El crecimiento demográfico de la población humana y el desarrollo económico asociado son considerados como fuerzas motrices siempre participantes del cambio medioambiental, e incluyen aspectos particulares que ejercen presión sobre el medioambiente, como la energía, el transporte, la urbanización y la globalización. La comprensión del crecimiento de estas fuerzas motrices y sus conexiones será de gran ayuda para atender su impacto colectivo y encontrar posibles soluciones, conservando con ello beneficios ambientales de los que dependen las sociedades humanas y las economías (UNEP, 2012).

\subsubsection{Población}

Un alto porcentaje de las presiones sobre el medioambiente, como la extracción de recursos, los patrones de producción y consumo, la emisión de contaminantes y desechos, el cambio de uso de la tierra, y la modificación y el movimiento de organismos son proporcionales al número de personas que dependen de los recursos naturales. Cuando una población crece más allá de la capacidad de carga de su ecosistema, se colapsa; algunas veces el ecosistema se recupera, pero en otras ocasiones queda alterado permanentemente. Esto ha ocurrido a las poblaciones humanas durante milenios; conforme crecen más allá de la capacidad de carga del medio que sostiene su sociedad, han tenido que enfrentar hambrunas, plagas o colapsos (Diamond, 2005).

La población humana alcanzó la cifra de 7.000 millones de personas en 2011 y se espera que llegue a los 10.000 millones para 2100 (United Nations [UN], 2011). Se proyecta que en 2050 el mayor crecimiento poblacional neto del mundo ocurrirá en las ciudades más pobres (UN, 2009) y que los cambios en la cobertura de la tierra tendrán lugar en ambientes rurales. La mayor huella que el hombre ha dejado sobre la superficie terrestre ha sido la conversión de los bosques en campos agrícolas. En la actualidad, el 37,4 \% de la superficie terrestre del planeta se utiliza para la producción agrícola (Foley et al., 2011). 


\subsubsection{Desarrollo económico}

La producción de bienes de consumo requiere de materiales y energía. Durante el siglo XX, la producción económica global creció más de veinte veces, mientras que la extracción de materiales creció hasta casi 60.000 millones de toneladas por año (Maddison, 2009). Este nivel de consumo de materiales por la población humana es de la misma escala que los principales flujos globales de materiales en los ecosistemas, tales como la cantidad de biomasa producida anualmente por las plantas verdes (Krausmann et al., 2009; UNEP, 2009).

La tecnología es un factor clave en la producción de bienes y servicios, y uno muy importante en términos del impacto ambiental. Se ha observado que factores de intensidad o calidad, que se ven afectados por la innovación tecnológica, pueden compensar los efectos adversos del aumento en la población, de modo que el crecimiento económico eventualmente conduzca a mejoras ambientales. Por otra parte, el cambio tecnológico que mejora la eficiencia del uso de recursos puede causar un efecto ambiental negativo al disminuir los costos del uso de los recursos, así como los precios de los productos y servicios, generando un aumento en la demanda. Si este incremento supera las ganancias en la eficiencia, el consumo global de un recurso puede aumentar, provocando incrementos adversos en el medioambiente (UNEP, 2012).

A medida que la población y el desarrollo económico han seguido creciendo, y a pesar de depresiones y descensos, las innovaciones tecnológicas han mejorado la integración de las comunidades y las sociedades en la civilización global. Los avances tecnológicos en temas energéticos y de transporte generan continuamente nuevas oportunidades para el crecimiento en la producción y el consumo, mientras que la inventiva aplicada a la comunicación y la movilidad ha creado nuevos bienes y servicios. El crecimiento y la integración de los asentamientos humanos, las sociedades y sus relaciones quedan de manifiesto por la rápida urbanización y globalización (UNEP, 2012).

\subsection{Tendencias medioambientales}

Las actuales tendencias medioambientales globales, como los gases de efecto invernadero, clima extremo, la disponibilidad de agua, la pérdida de biodiversidad y el manejo de desechos, entre otras, están generando nuevas amenazas, pero, a su vez, nuevas oportunidades para 
las empresas en todas las industrias. La transición hacia una economía más ecológica creará grandes oportunidades para las compañías que entiendan las implicaciones de estas tendencias y que las tomen en cuenta en su planificación y en su estrategia de negocios. Por el contrario, las empresas que no logren entender los cambios o que actúen con demasiada lentitud pondrán su valor en riesgo (UNEP, 2013). En la tabla 1 se muestran las principales tendencias medioambientales en la actualidad, así como las implicaciones clave para las empresas.

Las tendencias medioambientales no sólo impactan e influyen en los mercados, sino que impulsan la innovación tecnológica y el cambio, y estimulan reformas regulatorias y políticas a nivel nacional e internacional, a su vez representan oportunidades de negocio con respecto a la generación de nuevos tipos de bienes y servicios. Esta es la situación en la que las empresas deben actuar, ahora como en el futuro. A menos que se produzcan cambios dramáticos $\mathrm{e}$ inesperados en los factores que han llevado al desarrollo de estas tendencias, cabe esperar que las presiones ambientales aumenten en el futuro cercano, provocando cambios importantes no sólo en el entorno físico, sino también en el ámbito social, político y empresarial (UNEP, 2013).

\section{Tabla 1. Principales tendencias medioambientales}

\begin{tabular}{|c|c|}
\hline Tendencia medioambiental & Implicaciones clave para las empresas \\
\hline Gases de efecto invernadero & \multirow[b]{2}{*}{$\begin{array}{l}\text { - Cambios en el mercado que favorecen a los } \\
\text { productos con un menor aporte de carbono al } \\
\text { medioambiente. } \\
\text { - Alteraciones de las operaciones y cadenas de } \\
\text { suministro. } \\
\text { - Mayor costo de la energía, los alimentos y otras } \\
\text { materias primas. } \\
\text { - Cambios en los patrones de transporte y produc- } \\
\text { ción para adaptarse a las condiciones locales. }\end{array}$} \\
\hline $\begin{array}{l}\text { Las emisiones de gases de efecto invernadero } \\
\text { se duplicarán en los próximos cincuenta años. } \\
\text { Este crecimiento puede dar lugar a aumentos en } \\
\text { la temperatura promedio de la superficie de la } \\
\text { tierra a nivel global de } 3^{\circ} \mathrm{C} \text { a } 6^{\circ} \mathrm{C} \text { para finales } \\
\text { de siglo. }\end{array}$ & \\
\hline Condiciones meteorológicas severas & \multirow{2}{*}{$\begin{array}{l}\text { - Alteraciones en las operaciones y las cadenas de } \\
\text { suministro. } \\
\text { - Mayor costo de las operaciones y los materiales. } \\
\text { - Daños en la infraestructura pública. } \\
\text { - Aumento de la demanda de servicios de recons- } \\
\text { trucción. }\end{array}$} \\
\hline $\begin{array}{l}\text { Se presentó un aumento del } 230 \% \text { en el número } \\
\text { de desastres por inundaciones y un aumento del } \\
38 \% \text { en los desastres por sequía ocurridos entre } \\
1980 \text { y la década del } 2000 \text {. }\end{array}$ & \\
\hline
\end{tabular}




\begin{tabular}{|c|c|}
\hline Tendencia medioambiental & Implicaciones clave para las empresas \\
\hline Cambios en el uso de la tierra & \multirow{2}{*}{$\begin{array}{l}\text { - Nuevos y crecientes mercados como resultado de } \\
\text { la expansión urbana. } \\
\text { - Acceso restringido a los recursos de la tierra y } \\
\text { pérdida de servicios de los ecosistemas. } \\
\text { - Mayor competencia por el control de tierras cul- } \\
\text { tivables. } \\
\text { - Mayor presión para la protección de recursos na- } \\
\text { turales críticos. }\end{array}$} \\
\hline $\begin{array}{l}\text { Se proyecta un incremento en las necesidades de } \\
\text { tierra para usos urbanos de } 100 \text { a } 200 \text { millones } \\
\text { de hectáreas en los próximos cuarenta años. }\end{array}$ & \\
\hline Disponibilidad del agua & \multirow{2}{*}{$\begin{array}{l}\text { - Nuevos mercados para productos que utilicen el } \\
\text { agua de manera eficiente. } \\
\text { - Limitaciones en el crecimiento debido a la es- } \\
\text { casez del agua. } \\
\text { - Alteraciones en las operaciones y las cadenas de } \\
\text { suministro. } \\
\text { - Conflictos a causa del acceso limitado al agua. } \\
\text { - Aumento en los costos del agua. }\end{array}$} \\
\hline $\begin{array}{l}\text { La extracción de agua a nivel global se ha tripli- } \\
\text { cado en los últimos cincuenta años para satisfa- } \\
\text { cer la demanda agrícola, industrial y doméstica. }\end{array}$ & \\
\hline Contaminación c & \multirow{2}{*}{$\begin{array}{l}\text { - Mayor demanda de dispositivos y sistemas para } \\
\text { el control de la contaminación. } \\
\text { - Aumento en el costo del tratamiento del agua. } \\
\text { - Regulación más estricta con respecto a la cali- } \\
\text { dad del agua. } \\
\text { - Mayor demanda de servicios de atención médi- } \\
\text { ca para tratar los efectos negativos en la salud } \\
\text { por agua contaminada. }\end{array}$} \\
\hline $\begin{array}{l}\text { Agentes contaminantes químicos tóxicos per- } \\
\text { sistentes, que se encuentran en el } 90 \% \text { de los } \\
\text { cuerpos de agua, siguen acumulándose en los } \\
\text { sistemas acuáticos. }\end{array}$ & \\
\hline Exposición a & \multirow{2}{*}{$\begin{array}{l}\text { - Cambios en el mercado hacia productos "más } \\
\text { ecológicos". } \\
\text { - Restricciones en el uso de los productos. } \\
\text { - Mayor presión regulatoria por parte de los con- } \\
\text { sumidores y del público para garantizar mayor } \\
\text { transparencia. }\end{array}$} \\
\hline $\begin{array}{l}\text { Hay más de } 248.000 \text { productos químicos dispo- } \\
\text { nibles en el mercado, pero no hay información } \\
\text { sobre sus efectos individuales y sinérgicos sobre } \\
\text { la salud y el medioambiente. }\end{array}$ & \\
\hline Biodiversidad & \multirow{2}{*}{$\begin{array}{l}\text { - Mayor presión sobre el mercado, la reputación } \\
\text { de las empresas y los legisladores para reducir } \\
\text { los impactos en la biodiversidad. } \\
\text { - Aumento en el costo y reducción en la disponi- } \\
\text { bilidad de recursos escasos. } \\
\text { - Menos oportunidades para desarrollar productos } \\
\text { innovadores. } \\
\text { - Limitaciones en el acceso a la tierra. }\end{array}$} \\
\hline $\begin{array}{l}\text { Ecosistemas críticos, como los bosques, los } \\
\text { humedales y las tierras secas, siguen disminu- } \\
\text { yendo en superficie. Entre el } 2000 \text { y el } 2010 \text { se } \\
\text { perdieron } 13 \text { millones de hectáreas de bosque. } \\
\text { Se prevé que la extinción de especies continuará } \\
\text { a un ritmo elevado durante el siglo XXI. }\end{array}$ & \\
\hline & \multirow[b]{2}{*}{$\begin{array}{l}\text { - Mayores oportunidades de mercado para recu- } \\
\text { perar/reutilizar los desechos electrónicos. } \\
\text { - Mayor presión por parte de los consumidores y } \\
\text { legislación para reducir/gestionar los desechos. } \\
\text { - Efectos negativos en la imagen pública de las } \\
\text { empresas debidos a la falta de control de los } \\
\text { desechos. }\end{array}$} \\
\hline $\begin{array}{l}\text { Cada vez con mayor frecuencia, los materiales } \\
\text { se producen en una región, se utilizan en otra } \\
\text { y se desechan en una tercera. El tipo de dese- } \\
\text { chos que experimenta un mayor crecimiento en } \\
\text { el mundo, estimado en unas } 20 \text { a } 50 \text { millones de } \\
\text { toneladas al año, es la basura electrónica, que } \\
\text { contiene sustancias peligrosas y también meta- } \\
\text { les valiosos que pueden ser recuperados. }\end{array}$ & \\
\hline
\end{tabular}

Fuente: UNEP (2013). 


\subsection{Oportunidades de negocio}

En los siguientes apartados se presentan los diez sectores clave de actividad empresarial que, de acuerdo con el UNEP (2013) tienen mayor potencial y beneficio para el aprovechamiento de las oportunidades de negocio derivadas de las tendencias medioambientales actuales.

\section{Construcción y edificación}

- Aumento de la demanda de edificios e infraestructuras sustentables.

- Aumento de la demanda de los servicios de reparación y la reconstrucción de daños causados por tormentas; reconversión y desarrollo de tecnologías de alta eficiencia energética y edificación de estructuras resistentes al clima.

- Aumento de la demanda de procesos y materiales renovables, reciclados y que hacen un uso eficiente de los recursos.

- Aumento del valor de mercado de los edificios ecológicos.

- Aumento de la demanda de personas cualificadas en el diseño y la construcción sustentable.

- Beneficios en la imagen pública de la empresa debido a las certificaciones de construcción y diseño ecológicos.

2. Productos químicos

- Aumento de la demanda de componentes de eficiencia energética, tecnologías de energía renovable, tecnologías de tratamiento de agua e insumos agrícolas más sustentables.

- Aumento de la demanda de productos químicos ecológicos y desarrollo de modelos de negocio basados en el arrendamiento de productos químicos.

- Nuevas oportunidades de mercado para productos que puedan sustituir a los productos restringidos o que han sido retirados del mercado.

- Mejora en la imagen pública de la empresa gracias al uso de productos químicos ecológicos.

3. Energía eléctrica

- Aumento de la demanda de electricidad para la refrigeración de edificios y la recarga de vehículos eléctricos.

- Aumento de la demanda de electricidad de bajo contenido en carbono o a base de recursos renovables. 
- Nuevos modelos de negocio surgidos a causa de las acciones legislativas.

- Aumento de la demanda de tecnologías de redes eléctricas inteligentes, almacenamiento de energía y servicios de eficiencia energética.

4. Industrias extractivas

- Aumento de la demanda de ciertos minerales y materiales utilizados en aplicaciones de energías renovables, eficiencia energética, control de la contaminación del aire y tecnologías de purificación del agua.

- Aumento de la demanda de combustibles más limpios.

- Aumento de la demanda de minerales reciclados o más sustentables.

- Creación de nuevas oportunidades de exploración y extracción debido al aumento en las temperaturas en áreas previamente inaccesibles o poco rentables.

- Beneficios a la reputación de las empresas que sean consideradas parte de la solución al cambio climático.

- Desarrollo de nuevos mercados para tecnologías destinadas a la captura y almace- namiento del carbono y otras tecnologías para reducir las emisiones de carbono resultantes del uso de combustibles fósiles.

\section{Finanzas}

- Aumento de la demanda de seguros con cobertura de propiedades.

- Desarrollo de nuevos mercados para mecanismos financieros que reduzcan los riesgos o proporcionen rendimientos positivos o menores costos de capital para productos y servicios sustentables.

- Aumento de la demanda de capital para el financiamiento de soluciones ambientales.

- Aumento en la creación de oportunidades de inversión atractivas para proyectos ecológicos.

- Creación o expansión de mercados e inversiones en productos que incorporen criterios ambientales o soluciones específicas para cuestiones tales como el cambio climático.

- Ampliación de la demanda de productos de seguros que fomenten la construcción de viviendas e inmuebles de mayor eficiencia energética y tecnologías de energía renovable. 
6. Alimentos y bebidas

- Nuevos mercados para el suministro de alimentos alternativos o de variedades más resistentes al cambio climático.

- Oportunidades para las empresas en nuevas zonas de cultivo agrícola.

- Ampliación de los mercados de alimentos orgánicos y de la producción de alimentos sustentables.

- Beneficios a la reputación empresarial debido a la certificación de productos alimenticios sustentables.

7. Salud

- Mayor demanda de tratamientos de enfermedades causadas por los cambios ambientales y la exposición a la contaminación (por ejemplo, enfermedades cardiovasculares, respiratorias, infecciosas o transmitidas por el agua).

- Nuevos mercados para medicamentos que no requieran de agua limpia o de ser almacenados a temperaturas controladas.

8. Tecnologías de la información y la comunicación (TIC)

- Creación y expansión de mercados de productos que facili- ten las mejoras ambientales en otros sectores (por ejemplo, edificios inteligentes, transporte integrado, manufactura automatizada).

- Ampliación de los mercados que reemplacen a los bienes y servicios tradicionales con opciones virtuales.

- Ampliación de los mercados dedicados a recopilar y procesar datos ambientales.

- Beneficios para la reputación de las empresas que contribuyan a la solución de los problemas ambientales, como el cambio climático, la calidad y la disponibilidad del agua y la deforestación.

9. Turismo

- Mayor interés por visitar algunos destinos debido a los cambios ambientales.

- Aumento de la demanda del turismo de naturaleza, el ecoturismo y el agroturismo.

- Beneficios a la reputación y mayor demanda de empresas $\mathrm{y}$ destinos percibidos como ambientalmente responsables.

10. Transporte

- Mayor demanda de reducción de los costos e impactos ecológicos de la logística por parte de los clientes. 
- Creación y expansión de mercados que ofrezcan opciones de transporte menos contaminantes y de baja emisión de carbono (por ejemplo vehículos y combustibles).

- Nuevas rutas de transporte de carga que resulten de la disminución en los niveles del hielo marino.

Las presiones ambientales aumentarán en el futuro cercano, provocando cambios importantes no sólo en el entorno físico, sino también en el ámbito social, político y empresarial. Una estrategia a seguir para los empresarios que desean entender y abordar las oportunidades y los riesgos planteados por las tendencias medioambientales incluye los siguientes puntos (UNEP, 2013):

- Realizar un análisis profundo y específico de la empresa, con un enfoque de análisis de ciclo de vida, utilizando la información disponible sobre tendencias medioambientales, así como de los riesgos y oportunidades específicos para su sector de actividad empresarial, o tomando como referencia sectores afines o similares al suyo.

- Continuar mitigando los impactos de la empresa al medioambiente.
- Pensar estratégicamente sobre cómo debe cambiar la empresa para reflejar los cambios que se están produciendo en el medioambiente global y local.

- Presentar informes a las partes interesadas (inversionistas, empleados, clientes, comunidades, ONG y otros) sobre los impactos de la empresa en el medioambiente, los riesgos y las oportunidades que plantean las tendencias medioambientales y las estrategias para abordarlas.

- Trabajar junto con los responsables políticos para diseñar políticas públicas que fomenten prácticas empresariales sustentables.

- Colaborar para desarrollar soluciones altamente eficaces a los problemas creados por los cambios en el medioambiente.

\subsection{Ventaja competitiva}

De acuerdo con Porter (1989), para alcanzar el éxito competitivo, las empresas han de poseer una ventaja competitiva en forma de costos inferiores o productos diferenciados que obtengan precios superiores. Para mantener la ventaja, las compañías han de conseguir con el tiempo ventajas competitivas más refinadas, mediante la oferta de productos y servicios de calidad superior o mediante un proceso de producción más eficiente. 
Una empresa posee una ventaja competitiva cuando cuenta con una mejor posición que sus competidores para mantener a los clientes actuales, obtener nuevos y defenderse contra las fuerzas competitivas. Esta particularidad debe ser diferencial y sostenible a largo plazo. La ventaja competitiva nace fundamentalmente del valor que una empresa es capaz de crear para sus clientes, el cual exceda el costo en que incurre esa empresa por crearlo. El valor es lo que los compradores están dispuestos a pagar, y el valor superior resulta de ofrecer precios más bajos que los competidores por beneficios equivalentes o por proporcionar beneficios únicos que justifiquen un precio mayor (Porter, 1989).

La base para crear una ventaja comienza por el conocimiento del cliente, sus necesidades manifiestas y latentes, las tendencias de cambio de sus gustos, deseos y comportamiento, pues de ahí surge la oportunidad que podrá satisfacer la empresa siempre y cuando exista viabilidad técnica, comercial y económica para desarrollar la oferta, la cual será el soporte material de la ventaja competitiva así como el eje central de la entrega de valor para el cliente (Díaz, 2003).

La ventaja competitiva puede ser obtenida combinando, mediante una estrategia adecuada, los recursos productivos, las aptitudes del personal y las oportunidades del mercado, al mismo tiempo que se enfrentan las limitaciones de la empresa y los riesgos del entorno, estableciendo aquellas acciones que aseguren la sobrevivencia, el crecimiento y la rentabilidad del negocio a través del empleo óptimo de los recursos de la empresa. La búsqueda de la ventaja competitiva implica un análisis interno de las fortalezas y debilidades de la compañía, de las oportunidades del mercado y las amenazas existentes en el entorno, de tal manera que se asegure la plena adaptación de la empresa a su realidad empresarial (Porter, 1989).

Para Ohmae (1983), la estrategia consiste en un plan de acción para lograr un desempeño superior en relación con la competencia y los factores clave de éxito del negocio, combinando los puntos fuertes de la corporación y teniendo en cuenta la evolución del ambiente competitivo de la actividad en cuestión. Por su parte, Porter (1989) describe a la estrategia como la forma en que una empresa realiza sus actividades y organiza toda su cadena de valor para alcanzar una ventaja competitiva y un buen posicionamiento de la empresa en su industria.

Porter (1982) describió la estrategia competitiva, como el conjunto de 
las acciones ofensivas o defensivas de una empresa para crear una posición defendible dentro de una industria e identificó tres estrategias genéricas que pueden usarse para crear en el largo plazo una ventaja estratégica defendible, que sobrepase el desempeño de los competidores dentro de una industria. Esas tres estrategias genéricas son el liderazgo en costes, la diferenciación y el enfoque (también llamada estrategia de concentración, segmentación o especialización).

El liderazgo en costes es la estrategia con que la empresa se propone ser el productor de menor costo en su industria. Las fuentes de las ventajas en el costo son variadas y dependen de la estructura de la industria; pueden incluir la persecución de las economías de escala, acceso preferencial a materias primas, elevada eficiencia, gastos generales bajos, prestaciones limitadas de sus productos, disminución del desperdicio, control minucioso de operaciones y procesos, participación activa y motivada de los empleados en controlar y reducción constante de los costos (Porter, 1982).

Por su parte, la estrategia de diferenciación consiste en lograr desarrollar para el producto o servicio algo que sea percibido en toda la industria como único; se selecciona uno o más atributos que muchos compradores en una industria perciben como importantes y se enfoca en exclusiva a satisfacer esas necesidades. Su exclusividad es recompensada con un precio superior. La diferenciación puede basarse en el producto mismo, en el sistema de entrega, el medio del cual se vende, el enfoque de mercadotecnia, el servicio al cliente y la imagen de la empresa (Porter, 1982).

Finalmente, con la estrategia de enfoque se busca atender a una porción particular del mercado; se selecciona un grupo o segmento de mercado y se ajusta la estrategia a servirlos, excluyendo a los demás. Al optimizar la estrategia para los segmentos objetivo, se busca lograr una ventaja competitiva general. Esta estrategia competitiva es más eficaz cuando los consumidores tienen preferencia o necesidades distintivas, y cuando las empresas rivales no intentan especializarse en el mismo segmento de mercado.

Cada estrategia genérica posee un enfoque fundamentalmente diferente para crear y mantener una ventaja competitiva, combinándola con el panorama de su objetivo estratégico. El éxito de la estrategia depende de qué tan efectiva sea la empresa al manejar los cambios que se presenten en el ambiente competitivo. La globalización y el 
cambio tecnológico están creando nuevas formas de competencia; la desregularización está cambiando las reglas de la competencia en muchas industrias, los mercados se están volviendo más complejos e impredecibles, y los flujos de información en un mundo fuertemente interconectado están permitiendo a las empresas detectar y reaccionar frente a los competidores mucho más rápidamente (Porter, 1982).

Así, crear una ventaja competitiva requiere de una actitud estratégica de la organización en la búsqueda constante de nuevas fuentes de ventaja o de consolidar la existente, y ello implica un enfoque de la gerencia que estimule una actitud centrada en el aprendizaje tecnológico y que garantice la innovación y la adaptación tecnológica (Díaz, 2003).

\subsection{Tecnología e innovación}

La tecnología es una ventaja competitiva fundamental para las empresas. Desde la innovación y el desarrollo de nuevos productos y servicios, hasta el conocimiento especializado acerca de mercados o procesos industriales, la tecnología juega un papel principal en el éxito de las empresas nacionales e internacionales; además, es una base importante para el crecimiento económico y el desarrollo, por lo que los gobiernos necesitan implantar políticas que optimicen su generación y aplicación (Grosse, 1996).

La tecnología se clasifica de diversas formas; una de éstas es en tecnología de producto (el conocimiento utilizado para producirlo: especificaciones acerca de sus características y funcionalidades), tecnología de equipo (los conocimientos necesarios para la fabricación de equipo o maquinaria), tecnología de proceso (conocimiento usado en la producción para organizar los insumos y operar la maquinaria) y tecnología administrativa, también denominada de proceso administrativo (el conocimiento empleado en la operación de un negocio) (Grosse, 1996).

Otra tipificación de la tecnología es en dura y blanda. El término de tecnología blanda engloba los conocimientos de carácter no técnico, como la administración y la comercialización, ambos información no tangible, que permite a la empresa competir mediante el uso eficiente de sus recursos, en contraposición con la tecnología dura, que abarca la aplicación material de conocimientos técnicos en el diseño, producción y operación de maquinaria y equipo, fabricación de productos, insumos y materiales, así como para la prestación de servicios, estos 
últimos, entendidos como productos no tangibles (hotelería, viajes, banca y seguros, transportes, etc.).

Cada uno de estos tipos de tecnología puede ayudar a crear una ventaja competitiva para la empresa que los posea, siendo la transferencia tecnológica el principal proceso para acceder a ellos.

\subsection{Transferencia tecnológica}

La transferencia tecnológica es el proceso por medio del cual se transfieren habilidades, conocimiento, tecnologías, métodos y muestras de fabricación e instalaciones entre los gobiernos o las universidades $\mathrm{y}$ otras instituciones, para asegurar que los avances científicos y tecnológicos sean accesibles a un mayor número de usuarios que puedan desarrollar y explotar aún más esas tecnologías en nuevos productos, procesos, aplicaciones, materiales o servicios (Grosse, 1996).

Se puede clasificar a la transferencia tecnológica en vertical u horizontal, dependiendo de si el proceso cambia de investigación básica a aplicada o al desarrollo (transferencia vertical), o del uso de la tecnología en un lugar a su aplicación en otro (transferencia horizontal) (Grosse, 1996).
La transferencia tecnológica es el proceso por el cual se lleva a cabo la transmisión del saber hacer (knowhow), de conocimientos científicos y/o tecnológicos y de tecnología de una organización a otra. Se trata por tanto de un proceso de transmisión de conocimientos científicos y tecnológicos para desarrollar nuevas aplicaciones, por lo que es un factor crítico para el proceso de innovación y la competitividad (Consejo Aragonés de Cámaras de Comercio [CAC], 2016).

Las fuentes de transferencia de la tecnología son diversas y entre ellas pueden encontrarse las universidades, centros de investigación, laboratorios y otras empresas. Transferir tecnología implica adquirir, ceder, compartir, licenciar, acceder o posicionar conocimiento innovador en el mercado. Los mecanismos básicos de transferencia tecnológica son (CAC, 2016):

a. Contratos de transferencia tecnológica: Transferir tecnología implica adquirir, ceder, compartir, licenciar, acceder o posicionar conocimiento innovador en el mercado. Existen diversas modalidades de acuerdos de transferencia tecnológica. Contratos de Investigación y Desarrollo (I+D). 
- Contratos de Investigación y Desarrollo (I+D).

- Asesoría y consultoría científico tecnológica.

- Elaboración de informes, estudios o dictámenes.

- Servicios técnicos, pruebas y ensayos.

- Formación y capacitación para la transferencia de conocimientos y habilidades.

- Alquiler de equipo científico tecnológico (comodato).

b. Proyectos de Investigación, Desarrollo e Innovación $(\mathrm{I}+\mathrm{D}+\mathrm{I})$ colaborativa. Participación conjunta entre empresas, universidades y centros de investigación en proyectos de I+D+I. Normalmente, el proceso de transferencia tecnológica viene regulado por las bases de la convocatoria del proyecto (CAC, 2016).

c. Creación de Empresas de Base Tecnológica (EBT). Este mecanismo consiste en la puesta en marcha de un proyecto empresarial a partir de un proyecto anterior, bien sea universitario o empresarial (CAC, 2016), que basa su actividad en las aplicaciones de nuevos descubrimientos científicos o tecnológicos para la generación de nuevos productos, procesos o servicios (Escuela de Organización Industrial, 2010).
Las EBT enfocan su actividad empresarial a la innovación tecnológica orientada al mercado, dedicándose a la comercialización y rentabilización de productos y servicios innovadores generados a partir de un uso intensivo del conocimiento científico y tecnológico. Cuentan con una alta capacidad innovadora y disponen de equipos de trabajo integrados por personal científi$\mathrm{co}$, investigador y técnico altamente calificado y especializado (Observatorio Virtual de Transferencia de Tecnología, 2017).

d. Patentes y modelos de utilidad. Son títulos de propiedad que otorgan el derecho a explotar en exclusiva y en un país determinado una invención, impidiendo a otros explotarla comercialmente (CAC, 2016). Las características de los derechos de propiedad industrial son exclusividad, temporalidad y territorialidad (Instituto Mexicano de la Propiedad Industrial, 2016):

- Exclusividad. Se refiere al derecho que tienen los inventores o titulares de las creaciones frente a terceros contra el uso no autorizado de su invención (IMPI, 2016).

- Temporalidad. Los derechos de exclusividad son otorgados 
$\mathrm{y}$ válidos por un tiempo determinado e improrrogable. Al caducar, estos se extinguen y la creación industrial pasa al dominio público con el consecuente beneficio para la sociedad de disponer y explotar la creación sin autorización ni pago al inventor o titular (IMPI, 2016).

- Territorialidad. La protección de los derechos de propiedad industrial únicamente se otorga en el país donde ésta es solicitada y concedida; por lo tanto, si desea la misma protección de los derechos de propiedad industrial en el extranjero, deberá presentar la solicitud en cada país reclamando el derecho de prioridad (IMPI, 2016).

El conocimiento tecnológico generado por una EBT o por cualquier empresa puede ser rentabilizarlo a través de la explotación y comercialización con medios propios, lo que permite le permite a la compañía obtener una ventaja competitiva al ganar exclusividad en el mercado, aunque esta opción tiene un alto riesgo asociado, dado que los recursos que debe emplear son elevados. La empresa tiene la opción de la cesión o licencia de los derechos de sus innovaciones a un tercero, lo que le permite obtener ingresos, al mismo tiempo que le evita los riesgos relacionados con la explotación (CEVIPYME, 2015).

La diferencia entre la cesión y la licencia se resume en que en la primera los títulos de propiedad industrial pasan a ser titularidad de quien lo adquiere, tanto en sus obligaciones como en sus derechos, mientras que en la licencia, los derechos siguen perteneciendo al solicitante inicial (licenciante) y el licenciatario realiza un pago (regalía/royalty) por el derecho a la explotación exclusiva o no exclusiva de los mismos (CEVIPYME, 2015).

La transferencia tecnológica es una alternativa para rentabilizar la inversión realizada en la concepción y desarrollo de una invención patentable cuando no se puede llevar a cabo con garantías su producción (total o parcial), ni su posterior distribución comercial, ni su implantación en el proceso productivo (Instituto Nacional de Propiedad Industrial, 2016).

\section{METODOLOGÍA}

\subsection{Método de investigación}

El método o proceso de esta investigación se apega a las normas generales de la investigación científica, adaptándolas de acuerdo a los requerimientos del objeto de estudio, al 
alcance y las limitaciones de la misma (Rojas, 1999). Esta investigación se realiza en dos etapas (Hernández, Fernández \& Baptista, 2014):

Etapa 1. Establecimiento de la estrategia metodológica.

Etapa 2. Ejecución del trabajo empírico.

En la etapa de establecimiento de la estrategia metodológica, se concibe la idea de la investigación y se realiza la revisión de la literatura para delimitar el contexto del problema y plantear la situación problemática, las preguntas, los objetivos, la hipótesis y la justificación de la investigación. Después, se desarrolla el marco teórico y se establece el estado del arte, para continuar con la determinación del tipo de investigación en cuanto a su finalidad, alcance, corte y enfoque.
A continuación, se realiza la especificación y operacionalización de las variables, se selecciona el diseño apropiado de la investigación y finalmente, se establece la población y se determina la muestra de estudio (Hernández et al., 2014).

En la segunda etapa, de ejecución del trabajo empírico, se elabora el instrumento de medición y se realizan el pretest del instrumento y las pruebas de validez y confiabilidad del mismo (Méndez, 2006; Esquivel, 2013). Después, se organiza el trabajo de campo y se procede a la aplicación del instrumento elegido para la recopilación de los datos, los cuales se procesan, para su análisis, presentación de los resultados y conclusiones. Por último, se elabora el reporte final de la investigación. En la figura 1 se presentan los pasos del proceso de investigación. 


\section{Figura 1. Etapas del proceso de investigación}

\section{ETAPA 1. ESTRATEGIA METODOLÓGICA}

\section{Idea de investigación}

1. Elección de una idea novedosa, que sirva para la elaboración de teorías y la resolución de problemas.

2. Revisión bibliográfica.

\section{Problema de investigación}

1. Planteamiento del problema de investigación

2. Objetivos de investigación.

3. Preguntas de investigación

4. Hipótesis de investigación.

5. Justificación: relevancia y viabilidad.

\section{n!}

Marco teórico y estado del arte

1. Determinación de los ejes temáticos del problema de investigación.

2. Revisión de las investigaciones más importantes y los trabajos más recientes.

3. Identificación de los principales enfoques que han atacado el problema y sus avances a la fecha.

4. Análisis crítico de limitaciones de trabajos relacionados y propuestas para atacarlas.

5. Detección de nuevos problemas de investigación.

Tipo de investigación

1. Determinación del tipo de investigación: finalidad alcance, corte y enfoque.

Variables de investigación

1. Especificación de variables.

2. Operacionalización de variables.

Diseño de la investigación

1. Definición de la investigación: exploratoria descriptiva o correlacional.

Población y muestra de la investigación

1. Definición de la población.

2. Determinación de la muestra de estudio.

Fuente: elaboración propia con base en Hernández, Fernández y Baptista (2014), Méndez (2006) y Esquivel (2013).

\section{ETAPA 2. TRABAJO EMPIRICO}

Instrumento de medición

1. Diseño de instrumento.

2. Cálculo de validez y confiabilidad del instrumento

3. Ejecución del pretest.

Recolección de datos

1. Realización de entrevistas.

2. Aplicación de cuestionarios.

1. Codificación de datos.

2. Análisis descriptivo.

3. Análisis multivariable.

4. Análisis correlacional.

Informe

1. Resultados.

2. Conclusiones.

3. Limitaciones del estudio

4. Recomendaciones para futuras investigaciones.

Productos

1. Tesis doctoral

2. Artículo científico.

3. Memorias de presentaciones a Congresos
Procesamiento y análisis de datos 


\subsection{Planteamiento del problema}

El informe de competitividad global del Foro Económico Mundial (WEF, 2012; 2013; 2014; 2015 y 2016), así como el informe Doing Business del Banco Mundial (World Bank, 2013a; 2013ab, 2014; 2015; 2016) señalan que aunque la economía mexicana se ha mantenido en constante crecimiento, los avances en los indicadores de competitividad y de facilidad de realizar negocios en el país han mejorado poco en los cinco años recientes. Estos resultados de bajo rendimiento de la economía mexicana coinciden con el reporte de indicadores económicos clave de la industria manufacturera, publicado por la Secretaría de Economía (2012) que indican que, a excepción de las industrias automotriz y aeronáutica, el resto de las industrias manufactureras han mantenido un mínimo crecimiento en los últimos años.

En este contexto, las empresas enfrentan cambios constantes en su entorno y tienen que adaptarse rápida y eficazmente a esos cambios para sobrevivir. El fenómeno de la globalización de los mercados y el acelerado desarrollo de la tecnología y las comunicaciones obligan a las organizaciones a identificar y desarrollar ventajas competitivas, a brindar servicios y productos de calidad y a ofrecer valor agregado a sus clientes, buscando mejoras constantes en sus procesos y en cada etapa de su cadena productiva (Angulo, et al., 2003).

Las tendencias medioambientales propiciadas por el cambio medioambiental representan amenazas pero también ofrecen diversas oportunidades de negocio sustentables para diferentes sectores económicos e industrias, por la generación de nuevos tipos de bienes y servicios (UNEP, 2013), por lo que resulta relevante estudiar en qué medida las empresas mexicanas conocen y aprovechan estas nuevas oportunidades de negocio y cómo las integran dentro de su estrategia competitiva, lo cual constituye el objetivo principal de este trabajo de investigación.

\subsection{Problema de investigación}

El problema de investigación elegido es, ¿en qué medida las empresas mexicanas aprovechan las oportunidades de negocio de las tendencias medioambientales?

\subsection{Objetivos}

El objetivo general de la investigación, es determinar en qué medida las empresas mexicanas aprovechan las oportunidades de negocio de las tendencias medioambientales. 
Los objetivos específicos corresponden a determinar en qué medida las empresas identifican las oportunidades de negocio derivadas de las tendencias medioambientales, si reconocen cómo aprovecharlas y si les es posible acceder a dichas oportunidades para su beneficio. También buscan reconocer detalles acerca de los medios, recursos y estrategias que aplican.

\subsection{Justificación}

En la actualidad, la sociedad se enfrenta a un cambio de paradigma. En la actualidad, hemos pasado de la vieja creencia de que los recursos naturales son inagotables y de que tienen una capacidad ilimitada de regeneración, a reconocer que la naturaleza tiene límites y que la humanidad tiene la responsabilidad de asegurar que los ecosistemas y los ciclos naturales se mantengan en adecuado funcionamiento. Esta responsabilidad atiende a dos inquietudes que se han puesto como razón fundamental para la protección ambiental; por un lado, se ha reconocido el derecho a un desarrollo armónico con la naturaleza y, por el otro, se atiende a la necesidad de mantener un medioambiente que proporcione de forma sostenida los bienes y servicios necesarios para asegurar el bienestar de las personas incluyendo las más vulnerables, otorgándole mayor valor a la inclusión y al desarrollo social como parte fundamental del proyecto o intervención (UNEP, 2012).

Al realizar el análisis crítico de los trabajos relacionados, se ha encontrado una abundante cantidad de informes de evaluación del estado del medioambiente, del cambio medioambiental y las tendencias medioambientales en el mundo y en México, así como de trabajos de investigación relacionados con el medioambiente, el desarrollo sustentable y la economía verde tanto en el país como en el mundo. Por tanto, se considera relevante desarrollar un trabajo de investigación específico, que haga énfasis en cómo las empresas mexicanas, más allá de solo afrontar los retos de las tendencias medioambientales apegándose al cumplimiento la regulación gubernamental, pueden aprovechar las diversas oportunidades de negocio particulares para su sector e industria en el nuevo entorno de la economía verde, determinando si identifican las oportunidades de negocio derivadas de las mismas, si conocen cómo aprovecharlas y si les es posible acceder a ellas para su beneficio.

Así, se propone abordar desde una perspectiva original, proactiva $\mathrm{y}$ propositiva la problemática asociada a las tendencias medioambientales 
derivadas del cambio medioambiental, enfocándose en las empresas mexicanas, con el objetivo de identificar las diversas oportunidades de negocio en el marco de la economía verde, cuyo aprovechamiento sirve para impulsar el crecimiento económico, al mismo tiempo que se atiende al cuidado y se protege al medioambiente, apoyando así el desarrollo sustentable del país.

La relevancia de esta investigación se sustenta en: 1) la identificación de las diversas oportunidades de negocio de las tendencias medioambientales para las empresas mexicanas; 2) el valor de su aprovechamiento para fomentar el crecimiento y desarrollo económico sustentable, y 3) el cuidado y mejoramiento del medioambiente. Por su parte, la viabilidad de este trabajo se fundamenta en la disponibilidad de los recursos humanos, financieros, técnicos y operacionales, acordes a los alcances de la investigación propuesta y a la abundancia de fuentes de información, investigaciones, documentos de trabajo y datos estadísticos del área en que se enmarca el problema de investigación.

Así mismo, se plantea la hipótesis de que las empresas mexicanas aprovechan en baja medida las oportunidades de negocio de la economía verde; esto se afirman con base en la carencia de estudios, informes o experiencias de casos de éxito que hagan constancia del conocimiento y explotación eficiente de dichas oportunidades por parte de las empresas mexicanas.

Con respecto a la detección de nuevos problemas de investigación se encontró que hacen falta investigaciones específicas acerca del tema de si las empresas mexicanas se encuentran preparadas para enfrentar las amenazas del cambio medioambiental y las tendencias medioambientales, así como la forma y medida en que afrontan los riesgos y solventan sus vulnerabilidades.

Finalmente, el valor potencial de esta investigación se establece sobre los criterios de la implicación práctica del desarrollo de trabajos que aborden de forma específica el tema de investigación elegido: oportunidades de negocio y tendencias medioambientales en México, así como por la relevancia social que conlleva el mejoramiento de la competitividad empresarial, en beneficio por un lado, de las empresas nacionales al incrementar sus ventas, mercado, valor y rentabilidad y por el otro, del país, por el aumento del ingreso al erario y por la disponibilidad de mayores y mejores oportunidades laborales, de emprendimiento y de desarrollo, que 
contribuyan a mejorar el nivel de vida de la población.

\subsection{Tipo de investigación}

Esta investigación, en cuanto a su finalidad, es de tipo aplicada y tecnológica (Bunge, 2009). El problema a investigar se elige con un objetivo final definido y tiene como propósito primordial la resolución de problemas prácticosinmediatos. El objetivo general que aborda la investigación es determinar en qué medida las empresas mexicanas aprovechan las oportunidades de negocio de la economía verde, derivadas de las tendencias medioambientales.

Respecto a su alcance, es una investigación de tipo correlacional, en la que se busca conocer el comportamiento de una variable, a través del comportamiento de otras variables relacionadas. Esta investigación describe las relaciones entre la variable dependiente y las variables independientes (Sierra, 2008; Méndez, 2006).

Atendiendo a su dimensión temporal, el tipo de investigación es de corte transversal, ya que se realiza en un único lapso (Sierra, 2008; Méndez, 2006). La aplicación del instrumento se realiza durante dos meses. Una vez concluido el trabajo de campo, los datos recopilados se procesan, para su análisis, conclusiones y presentación de los resultados.

Finalmente, la metodología de la investigación tiene un enfoque mixto, cuantitativo y cualitativo (Bunge, 1990), y utiliza la recopilación, procesamiento y análisis de datos para contestar las preguntas de investigación y probar las hipótesis establecidas, con base en la medición numérica y el análisis estadístico, para establecer patrones de comportamiento de la población (Hernández, Fernández \& Baptista, 2014).

\subsection{Tipo de diseño de la investigación}

El tipo de diseño de esta investigación es no experimental (Kelinger \& Lee, 2008). Su objetivo es observar y determinar la relación entre las variables en su contexto; no se pretende la manipulación de las variables, ni de sus condiciones. Se observan situaciones ya existentes, tal y como se dan en su contexto natural, no provocadas por el investigador, para después analizarlas. No se introducen condiciones ni estímulos a los que se expongan los sujetos de estudio, sino que son observados en su ambiente natural sin la intervención directa del investigador (Hernández, et al., 2014). 


\subsection{Universo y Población}

\subsubsection{Universo}

El universo de la investigación comprende el total de empresas de los diferentes sectores económicos ubicadas en la república mexicana que, de acuerdo conel último censo de población del año 2013, asciende a 4.230.745 (INEGI, 2016b).

\subsubsection{Población}

La población de estudio se encuentra conformada por las empresas del sector de la Construcción, establecidas en la Zona metropolitana del Valle de México (ZMVM) (Secretaría de Desarrollo Social, Consejo Nacional de Población e Instituto Nacional de Estadística y Geografía [INEGI], 2012; 2016a).

La elección del espacio geográfico de la Zona Metropolitana del Valle de México (ZMVM) como fuente de las unidades de observación de la muestra de estudio de este trabajo de investigación, obedece a su relevancia demográfica y económica, ya que es la zona metropolitana (ZM) más importante del país. Para el 2010 , en ella habitaba el $17,9 \%$ de la población nacional y en el 2013, en esta zona se ubicó el 23,6 \% de la fuerza laboral, y se generó el 26,3 \% de la producción bruta total del país (INEGI, 2016a).

Por su parte, la elección de empresas del sector de la Construcción como unidades de observación de este trabajo de investigación, se sustenta en los siguientes puntos:

1. La relevancia de este sector económico por su contribución a la producción nacional, el número de unidades económicas y el personal ocupado (INEGI, 2015a; 2015b; 2015c), cuyos indicadores económicos clave se presentan en la tabla 2 (INEGI, 2016c).

2. Su relación directa con los demás sectores económicos, todos los cuales poseen o utilizan edificios, instalaciones e infraestructura, y por sus vínculos con otros sectores en los que se apoya y a los cuales beneficia, como el sector de Minería, el deEnergía, el de Manufacturas, el de Comunicaciones y el de Transportes (UNEP, 2013).

3. La disponibilidad de los recursos humanos, financieros, técnicos y operacionales, acordes a los alcances de esta investigación, que permiten la realización del trabajo en campo para el tamaño de muestra correspondiente a este sector económico. 
Tabla 2. Sector de la Construcción por tamaño de unidad económica

\begin{tabular}{|c|c|c|c|c|c|c|}
\hline \multirow{2}{*}{$\begin{array}{c}\text { Tamaño de la } \\
\text { unidad }\end{array}$} & \multicolumn{2}{|c|}{ Unidades económicas* } & \multicolumn{2}{|l|}{ Personal Ocupado Total } & \multicolumn{2}{|c|}{$\begin{array}{c}\text { Producción Bruta Total } \\
\left(\mathrm{PBT}^{* *}\right)\end{array}$} \\
\cline { 2 - 7 } & Absoluto & Porcentual & Absoluto & Porcentual & Absoluto & Porcentual \\
\hline $\begin{array}{c}\text { "(Micro) Hasta 10 } \\
\text { personas" }\end{array}$ & 7.803 & 45,7 & 35.432 & 6,2 & 14.854 .712 & 4,3 \\
\hline $\begin{array}{c}\text { "(Pequeña) 11 a 50 } \\
\text { personas" }\end{array}$ & 6.900 & 40,4 & 159.471 & 28,0 & 64.349 .888 & 18,6 \\
\hline $\begin{array}{c}\text { "(Mediana) 51 a } \\
250 \text { personas" }\end{array}$ & 2.069 & 12,1 & 209.010 & 36,7 & 118.957 .618 & 34,3 \\
\hline $\begin{array}{c}\text { "(Grande) 251 y } \\
\text { más personas" }\end{array}$ & 291 & 1,7 & 165.943 & 29,1 & 148.565 .061 & 42,8 \\
\hline Total nacional & 17.063 & 100 & 569.856 & 100 & 346.727 .279 & 100 \\
\hline
\end{tabular}

* Censos Económicos 2014.

*** PBT: Producción Bruta Total.

Fuente: Instituto Nacional de Estadística y Geografía (2016c).

\subsection{Muestra de estudio}

\subsubsection{Tamaño de muestra}

Al no contar con datos acerca del número de unidades económicas agrupados a nivel de Zona Metropolitana, ni segmentados a nivel delegación y municipio, se emplean los valores obtenidos en conjunto para el total de las unidades económicas del sector de la Construcción ubicadas en la Ciudad de México (1617), el estado de México (913) y el estado de Hidalgo (329), contando así con un total de 2859, teniendo en cuenta que su número combinado integra y supera al de las unidades económicas localizadas en la ZMVM (INEGI, 2016d).
El tamaño de la muestra de estudio se obtuvo utilizando la fórmula para poblaciones finitas, comparando los valores estándar de nivel de confianza alto del $95 \%$, con error de estimación del $5 \%$, contra nivel de confianza del $90 \%$ con error de estimación del $10 \%$. Eligiendo la muestra con el mayor nivel de confianza posible, de acuerdo con los recursos disponibles para la realización del estudio (Hernández, Fernández y Baptista, 2014), se determinó adecuado elegir el tamaño de muestra de nivel de confianza del $90 \%$ con error de estimación del $10 \%$, ya que se desea un nivel alto de confianza y se estima que es posible cubrir ese tamaño de muestra con los recursos disponibles, por lo 
que el tamaño de muestra elegido es de 249 empresas.

\subsubsection{Tipo de muestreo}

El tipo de muestreo utilizado es aleatorio estratificado (también denominado muestreo probabilístico estratificado) (Hernández, Fernández \& Baptista, 2014), por tamaño de establecimiento, teniendo en cuenta el personal ocupado; está compuesto por cuatro estratos: Micro, Pequeña, Mediana y Gran empresa (INEGI, 2015d).

El conjunto de todos los estratos representa al sector de la Construcción, integrado por los subsectores de edificación residencial y no residencial, construcción de obras de ingeniería civil y la realización de trabajos especializados para la construcción (INEGI, 2013). Para cada estrato se obtiene una muestra independiente que lo representa.

\subsubsection{Estratificación de la muestra}

Se realizó la estratificación de la muestra atendiendo a los criterios establecidos por el Instituto Nacional de Estadística y Geografía (INEGI) para el tamaño de establecimiento por personal ocupado en: 1) Micro (Hasta 10 personas), 2) Pequeña (11 a 50 personas), 3) Mediana (51 a 250 personas) y 4) Grande (251 y más personas) (INEGI, 2015d).

En cuanto al número de unidades económicas del Sector de la Construcción, correspondientes al espacio geográfico de la Zona Metropolitana del Valle de México (ZMVM), están conformadas por 33 localidades que pertenecen a las 16 delegaciones de la Ciudad de México; siete localidades del municipio Tizayuca, del estado de Hidalgo, y 227 localidades de 59 de los 125 municipios del estado de México (SEDESOL, CONAPO \& INEGI, 2012; INEGI, 2016a); al no disponer de datos agrupados a nivel Zona Metropolitana, ni segmentados a nivel delegación y municipio, se emplean los valores obtenidos para el total de las unidades económicas del sector de la Construcción, ubicadas en la Ciudad de México (1617), el estado de México (913) y el estado de Hidalgo (329), apreciando que su suma integra satisfactoriamente las unidades económicas localizadas en la ZMVM (INEGI, 2016d). La estratificación de la muestra, según lo expuesto, se presenta en la tabla 3. 
Tabla 3. Estratificación de la muestra de estudio

\begin{tabular}{|c|c|c|c|c|c|}
\hline \multirow{3}{*}{$\begin{array}{l}\text { Tamaño de la } \\
\text { unidad }\end{array}$} & \multicolumn{3}{|c|}{$\begin{array}{l}\text { Sector de la Construcción. Unidades } \\
\text { económicas }{ }^{1}\end{array}$} & \multirow{2}{*}{\multicolumn{2}{|c|}{$\begin{array}{c}\text { Estratificación de la muestra } \\
\text { Confiabilidad }\end{array}$}} \\
\hline & \multirow{2}{*}{$\begin{array}{l}\text { "Composición } \\
\text { Porcentual" }\end{array}$} & \multirow{2}{*}{ Nacional } & \multirow{2}{*}{ ZMVM* } & & \\
\hline & & & & $95 \%$ & $90 \%$ \\
\hline $\begin{array}{l}\text { "(Micro) Hasta } 10 \\
\text { personas" }\end{array}$ & 45,73 & 7.803 & 1.307 & 155 & 114 \\
\hline $\begin{array}{l}\text { "(Pequeña) } 11 \text { a } \\
50 \text { personas" }\end{array}$ & 40,44 & 6.900 & 1.156 & 137 & 101 \\
\hline $\begin{array}{l}\text { "(Mediana) } 51 \mathrm{a} \\
250 \text { personas" }\end{array}$ & 12,13 & 2.069 & 347 & 41 & 30 \\
\hline $\begin{array}{l}\text { "(Grande) } 251 \mathrm{y} \\
\text { más personas" }\end{array}$ & 1,71 & 291 & 49 & 6 & 4 \\
\hline Total & 100,00 & 17.063 & 2.859 & 339 & 249 \\
\hline
\end{tabular}

Fuente: SEDESOL, CONAPO e INEGI (2012) e INEGI (2015d, 2016a y 2016d).

\subsection{Selección del instrumento}

Las técnicas de investigación empleadas fueron observación por preguntas y encuesta, con la aplicación de las herramientas de investigación de entrevista y cuestionario (Kerlinger \& Lee, 2008; Padua, 2001). Se emplearon ítems de nivel ordinal relacionados con los factores que afectan el aprovechamiento de las oportunidades de negocio de las tendencias medioambientales, conocimiento, disponibilidad de recursos y actitud innovadora, medidos a través de una escala de actitud tipo Likert con cinco opciones. Las puntuaciones correspondientes se obtienen mediante la suma de los valores obtenidos para cada aseve- ración (Hernández at al., 2008); entre más favorable sea la valoración mayor será la puntuación y se obtiene una menor puntuación en el caso contrario.

La puntuación de cada ítem se obtiene conforme a las cinco opciones propuestas en la escala, cuya codificación es la siguiente: (1) Totalmente de acuerdo, (2) De acuerdo, (3) Ni de acuerdo, ni en desacuerdo, (4) En desacuerdo, (5) Totalmente en desacuerdo.

Se elaboró el instrumento de medición y se obtuvieron los resultados del pre-test así como los de las pruebas de validez y confiabilidad del mismo. 


\section{RESULTADOS Y DISCUSIÓN}

Para el procesamiento y análisis de los datos recopilados se aplicaron pruebas estadísticas paramétricas: 1) Medidas de posición central: media,modaymediana;2)Medidas para establecer la distribución de los valores de la serie y su concentración o dispersión: varianza, desviación estándar y coeficiente de variación de Pearson. Pruebas de normalidad de la muestra $(z>0,9)$ : Prueba de Kolmogorov-Smirnov (corrección de la significación de Lilliefors) y prueba de Shapiro-Wilk. Pruebas de fidelidad del instrumento $(\mathrm{z}>0,8)$ : coeficiente Alfa de Cronbach y coeficiente de las Dos Mitades (Split Half). Pruebas de correlación de las variables de investigación: coeficiente de correlación de Pearson y coeficiente de determinación, para lo cual se empleó el Software IBM SPSS versión 19.0.

Los resultados obtenidos indican una relación lineal positiva y alta entre las variables de estudio: coeficiente de correlación de Pearson $(0,81<\mathrm{r}<0,87)$ y coeficiente de determinación $\left(0,6561<\mathrm{r}^{2}<0,7569\right)$, lo que implica que el conocimiento de las tendencias medioambientales, la disponibilidad de recursos técnicos, económicos y humanos, y la actitud innovadora permiten a las empresas aprovechar las opor- tunidades de negocio derivadas del cambio medioambiental, independientemente del tamaño de la empresa, lo cual puede incidir de forma directa y positiva en la competitividad de las empresas mexicanas.

Además, se encontró que las empresas de tamaño grande (251 y más personas) (INEGI, 2015d) casi no realizan inversión en Investigación, Desarrollo e Innovación (I+D+I) de nuevos procesos, productos o servicios sustentables, presentan mínima transferencia y adopción tecnológica y se encuentran al tanto de las nuevas innovaciones tecnológicas en desarrollo de materiales y productos para la construcción, cuyo desarrollo y fabricación corresponde al sector de Industrias Manufactureras, del cual se abastece, y en particular a los subsectores económicos de industria de la madera, fabricación de productos derivados del petróleo y del carbón, industria química, industria del plástico y del hule, fabricación de productos a base de minerales no metálicos, industrias metálicas básicas, fabricación de productos metálicos, fabricación de maquinaria y equipo y fabricación de accesorios, aparatos eléctricos y equipo de generación de energía eléctrica (INEGI, 2013). También están al tanto de las nuevas tendencias de edificación sustentable, aunque no las promueven 
activamente entre sus clientes. Los productos de tecnología sustentable que mayormente proveen son los relacionados con la edificación de edificios inteligentes, el diseño e instalación de jardines verticales y azoteas verdes, los proyectos de eficiencia energética y los sistemas para el tratamiento y reutilización de aguas residuales industriales, aunque sus actividades económicas principales no incluyen la comercialización directa al mayoreo o menudeo de insumos o productos para la construcción (INEGI, 2013). Así mismo, conocen y cumplen con la normatividad vigente sobre auditoria de impacto ambiental, incluso con la de carácter de cumplimiento voluntario.

Por su parte, las empresas que formaron parte de la muestra de estudio, clasificadas como medianas (51 a 250 personas) (INEGI, 2015d) sí comercializan e instalan con regularidad productos de tecnología sustentable, aunque no corresponde a la clasificación de su actividad económica principal (INEGI, 2013); entre estos productos se encuentran paneles y calentadores solares, canceles, plafones y paneles, términos aislantes para el ahorro de energía en calefacción, ventilación y aire acondicionado (HVAC), y sistemas para captación de agua de lluvia, filtración y tratamiento para potabilizarla; por otra parte, no informaron la realización de acciones de $\mathrm{I}+\mathrm{D}+\mathrm{I}$ de procesos, productos o servicios sustentables. Estas empresas son reticentes a cumplir con la normatividad sobre impacto ambiental, así como a la adopción de buenas prácticas de construcción sustentable para la mitigación de impactos ambientales en cada una de las actividades asociadas al desarrollo de procesos constructivos, como son el manejo de residuos, el control de emisiones atmosféricas, la prevención de la contaminación del agua, $y$ el uso y almacenamiento adecuado de materiales de construcción.

Finalmente, en las empresas de tamaño pequeño (11 a 50 personas) y micro (hasta 10 personas) (INEGI, 2015d) destaca positivamente el hecho de que, aunque en un porcentaje muy bajo, algunos microemprendimientos con mínimos recursos económicos $\mathrm{y}$ en forma semiartesanal, se encuentran interesados e inmersos en el desarrollo de productos sustentables, sobre todo de de materiales para la construcción obtenidos a partir del reciclaje y el aprovechamiento de desperdicios tanto industriales como urbanos, aunque esta actividad económica corresponda al sector de industrias manufactureras (INEGI, 2013). Así mismo, florecen pequeños despachos de diseño arquitectónico que buscan sustentar su ventaja competitiva por medio de 
la diferenciación de sus servicios, al ofrecer a sus clientes alternativas de "edificación pasiva", que toman en cuenta las condiciones climáticas, (sol, lluvia, viento, etc.) para disminuir los impactos ambientales y reducir el consumo de energía. Aparte de estas excepciones, se encontró que, en general, las empresas de tamaño pequeño y micro no se encuentran al tanto ni de las tendencias medioambientales, ni de las posibles oportunidades de negocio derivadas de las mismas; al ser informadas al respecto, afirman que no cuentan con medios económicos, técnicos y humanos para intentar explorar y explotar estas nuevas oportunidades.

\section{CONCLUSIONES}

Esta investigación se propuso abordar la problemática asociada al cambio medioambiental, desde una perspectiva original, proactiva y propositiva, con enfoque particular en las empresas de México, que permitiera identificar las diversas oportunidades de negocio derivadas de las tendencias medioambientales, en el marco de la economía verde, cuyo aprovechamiento sirva para impulsar el crecimiento económico, atender el cuidado y protección del medioambiente y apoyar el desarrollo sustentable de la nación.
Los resultados obtenidos en esta investigación aportan evidencia empírica acerca de que es posible para las empresas mexicanas aprovechar las oportunidades de negocio derivadas del cambio medioambiental, independientemente del tamaño de la empresa, por medio del conocimiento de las tendencias medioambientales, la disponibilidad de recursos técnicos, económicos y humanos, y la actitud innovadoray emprendedora, cumpliendo de manera satisfactoria el objetivo de esta investigación.

El valor potencial de esta investigación se establece sobre los criterios de la implicación práctica del desarrollo de trabajos que aborden de forma específica el tema de investigación elegido, oportunidades de negocio y tendencias medioambientales, así como por la relevancia social que conlleva el mejoramiento de la competitividad empresarial en beneficio, por un lado, de las empresas nacionales al incrementar sus ventas, mercado, valor y rentabilidad y por el otro, del país, por el aumento del ingreso al erario y por la disponibilidad de más y mejores oportunidades laborales, de emprendimiento y de desarrollo, que contribuyan a mejorar el nivel de vida de la población. 
Limitaciones y recomendaciones para futuras investigaciones

Dentro de las limitaciones de este trabajo de investigación se puede mencionar que no fueron abarcadas empresas de todos los sectores económicos ni de todos los estados del país.

Para futuras investigaciones se realizan las siguientes recomendaciones:

- Efectuar y comparar estudios específicos por sector económico e industria, a nivel nacional, estatal, regional y de zona metropolitana (SEDESOL, CONAPO e INEGI, 2012; INEGI, 2016a).

- El estudio de corte transversal efectuado permitió observar la situación de las empresas en un momento determinado y sería recomendable un estudio longitudinal para comparar los procesos de evolución y conocer así el impacto en el corto, mediano y largo plazo.

\section{REFERENCIAS}

Angulo, J. L., Franco, A., López, M., Nájera, J., \& Pérez, N. (2003). Propuesta de diseño del sitio web para una empresa del sector textil, como estrategia de marketing. México: Instituto Politécnico Nacional.
Banco Mundial. (2016) Doing Business en México 2016. Midiendo la calidad y la eficiencia de regulación. Washington, D.C.: Grupo del Banco Mundial.

Bunge, M. (1990). La ciencia. Su método y su filosofía. México: Grupo Patria Cultural.

Bunge, M. (2009). Estrategias de la investigación científica. Perú: Universidad Inca Garcilaso de la Vega.

CEVIPYME. (2015). Empresas de base tecnológica. CEVIPYME. Recuperado de http://www.cevipyme.es/herramientas/documentacion/Paginas/

Consejo Aragonés de Cámaras de Comercio. (2016). Innovación. Propiedad Industrial e Intelectual. Transferencia de Tecnología. Recuperado de http://www.camarasaragon.com/innovacion/PropiedadTransferenciaTecnologia.asp

Diamond, J. (2005). Collapse: How Societies Choose to Fail or Succeed. New York: Viking Press.

Díaz, I. (2003). Marketing y competitividad: ¿Relación o contradicción? Economía y Desarrollo, 132(1), pp. 112-119.

Escuela de Organización Industrial. (2010). Análisis de la situación competitiva de las empresas de base tecnológica españolas. Madrid: EOI.

Esquivel, F. (2013). Lineamientos para diseñar un estado de la 
cuestión en investigación educativa. Revista Educación, 37(1), pp. 65-87.

Foley, J.A., Ramankutty, N., Brauman, K.A., Cassidy, E.S., Gerber, J.S., Johnston, M.,... Zaks, D.P.M. (2011). Solutions for a cultivated planet. Nature, (478), pp. 337-342.

Grosse, R. (1996). International Technology Transfer in Services. Journal of International Business Studies. 27(4):781-800, 27.

Grupo Intergubernamental de Expertos sobre el Cambio Climático. (2002). Cambio Climático y Biodiversidad. Documento técnico V del IPCC. Ginebra: IPCC.

Hargroves, K. J., \& Smith, M. H. (editors). (2005). The Natural Advantage of Nations: Business Opportunities, Innovations and Governance in the 21st Century. United Kingdom: Earthscan.

Hernández, R., Fernández, C., \& Baptista, P. (2014). Metodología de la investigación. México: Mc Graw-Hill Interamericana.

Herrán, C. (2012). El Camino hacia una economía verde. Proyecto Regional de Energía y Clima. México: Fundación Friedrich Ebert.

Instituto Mexicano de la Propiedad Industrial. (2016). Guía sobre invenciones. Patentes, Modelos de Utilidad, Diseños Industriales y Esquemas de Trazado de Circuitos Integrados. México: IMPI.
Instituto Nacional de Estadística y Geografía. (INEGI). (2013). Sistema de Clasificación Industrial de América del Norte, México: SCIAN 2013 / Instituto Nacional de Estadística y Geografia. México: INEGI.

Instituto Nacional de Estadística y Geografía. (INEGI). (2015a). Censos Económicos 2014. Resumen de los resultados definitivos. México: INEGI.

Instituto Nacional de Estadística y Geografía. (INEGI). (2015b). Censos Económicos 2014. Datos relevantes de los resultados definitivos. [Boletín de prensa No. 283/15], 28 de julio de 2015, pp. 1-2.

Instituto Nacional de Estadística y Geografía. (INEGI). (2015c). Censos Económicos 2014. Resultados definitivos. Julio de 2015. México: INEGI.

Instituto Nacional de Estadística y Geografía (INEGI). (2015d). Censos Económicos 2014. Micro, pequeña, mediana y gran empresa. Estratificación de los Establecimientos. México: INEGI.

Instituto Nacional de Estadística y Geografía (INEGI). (2016a). Censos Económicos 2014. Zonas Metropolitanas de los Estados Unidos Mexicanos. México: INEGI.

Instituto Nacional de Estadística y Geografía (INEGI). (2016b). 
Censos Económicos 2014. Las empresas en México. México: INEGI.

Instituto Nacional de Estadística y Geografía (INEGI). (2016c). Censos Económicos 2014. Construcción. Conociendo México. México: INEGI.

Instituto Nacional de Estadística y Geografía (INEGI). (2016d). Características principales de las unidades económicas del sector privado y paraestatal que realizaron actividades en 2013, según entidadfederativa y actividad. Datos de 2013. Fecha de actualización: 03/05/2016. México: INEGI.

Instituto Nacional de Propiedad Industrial (INAPI). (2016). ¿Qué es la Transferencia de Tecnología o Transferencia Tecnológica? Recuperado de http://www.inapi.cl/ portal/orientacion/602/w3-article-693.html

Kerlinger, F., \& Lee, H. (2008). Investigación del Comportamiento. Métodos de Investigación en Ciencias Sociales Cuarta edición. México: Mc Graw Hill Interamericana.

Krausmann, F., Gingrich, S., Eisenmenger, N., Erb, K.-H., Haberl, H., \& Fischer-Kowalski, M. (2009). Growth in Global Materials Use, GDP and Population During the 20th Century. Ecological Economics, 68(10), pp. 2696-2705.
Lara, T., Lizarralde, E., \& Ferro, E. (directores). (2010). Sectores de la nueva economía 20+20. Economía Verde. Madrid: Escuela de Organización Industrial, Ministerio de Industria, Turismo y Comercio.

Maddison, A. (2009). Historical Statistics for the World Economy: 1-2001 AD. Recuperado de: http://www.ggdc.net/maddison/

Méndez, C. (2006). Metodología diseño y desarrollo del proceso de investigación con énfasis en ciencias empresariales. Bogotá: Limosa Noriega Editores.

Observatorio Virtual de Transferencia de Tecnología. (2017). Empresas de Base Tecnológica. Recuperado de http://www.ovtt. org/empresa-base-tecnologica

Ohmae, K. (1983). La mente del estratega. México: Mc Graw Hill.

Padua, J. (2001). Técnicas de Investigación Aplicadas a las Ciencias Sociales. México: COLMEXFondo de Cultura Económica.

Porter, M. (1982). Estrategia competitiva. México: CECSA.

Porter, M. (1989). Ventaja competitiva. México: CECSA.

United Nations Environment Programme (UNEP). (1987). Informe de la Comisión Mundial sobre el Medio Ambiente y el Desarrollo (Comisión Brundtland): Nuestro Futuro Común. Oxford: Oxford University Press. 
United Nations Environment Programme (UNEP). (2012). Economía Verde en el Contexto del Desarrollo Sostenible y Erradicación de la Pobreza: Una Perspectiva desde América Latina y el Caribe. UNEP/LAC-IG. XVIII/3. Quito: UNEP.

United Nations Environment Programme (UNEP). (2009). Nuevo Acuerdo Verde Global. Informe de Politica. Nueva York: UNEP.

Rojas, R. (1999). Guía para realizar investigaciones sociales. México: Plaza y Valdez.

Secretaría de Desarrollo Social, Consejo Nacional de Población e Instituto Nacional de Estadística y Geografía. (2012). Delimitación de las zonas metropolitanas de México 2010 Primera Edición. México: SEDESOL, CONAPO e INEGI.

Secretaría de Economía (2012). Industria Manufacturera de México. México: Secretaría de Economía.

Secretaría de Medio Ambiente y Recursos Naturales (SEMARNAT) e Instituto Nacional de Ecología y Cambio Climático. (2014). Avances del Estudio de Economía Verde para México. México: SEMARNAT-INECC.

Serrano, A., \& Carrillo, S. M. (2011). La Economía Verde desde una perspectiva de América Latina. Ecuador: Fundación Friedrich Ebert.
Sierra, R. (2008). Técnicas de Investigación Social. Teoría y Ejercicios. Madrid: Thompson.

United Nations. (2009). World Urbanization Prospects: The 2009 Revision. Population Division, Department of Economic and Social Affairs. Recuperado de http:// esa.un.org/unpd/wup/index.htm

United Nations. (2011). World Population Prospects: The 2010 Revision. Population Division, Department of Economic and Social Affairs. New York: United Nations.

United Nations Environment Programme. (2009). United Nations Environment Programme Year Book: Resource Efficiency. Nairobi: UNEP.

United Nations Environment Programme. (2012). GEO-5 Perspectivas del Medio Ambiente Mundial. Medio ambiente para el futuro que queremos. Nairobi: UNEP.

United Nations Environment Programme. (2013). GEO-5 for Business. Impacts of a Changing Environment on the Corporate Sector. Nairobi: UNEP.

World Bank. (2013a). Doing Business 2013: Smarter Regulations for Small and Medium-Size Enterprises. Washington, D.C.: World Bank Group.

World Bank. (2013b). Doing Business 2014: Understanding Regulations for Small and Medium- 
Size Enterprises. Washington, D.C.: World Bank Group.

World Bank. (2014). Doing Business 2015: Going Beyond Effcience. Washington, D.C.: World Bank.

World Bank. (2016). Doing Business 2016: Measuring Regulatory Quality and Efficiency. Washington, D.C.: World Bank. World Bank. (2017). Doing Business 2017: Equal Opportunity for All. Washington, D.C.: World Bank.

World Economic Forum. (2012). The Global Competitiveness Report 2012-2013. Insight Report. Geneva: WEF.
World Economic Forum. (2013). The Global Competitiveness Report 2013-2014. Insight Report. Full Data Edition. Geneva: WEF.

World Economic Forum. (2014). The Global Competitiveness Report 2014-2015. Insight Report. Geneva: WEF.

World Economic Forum. (2015). The Global Competitiveness Report 2015-2016. Insight Report. Geneva: WEF.

World Economic Forum. (2016). The Global Competitiveness Report 2016-2017. Insight Report. Geneva: WEF. 